\title{
A method to guide community planning and evaluation efforts in tobacco control using data on smoking during pregnancy
}

\author{
V H Newburn, P L Remington, P E Peppard
}

Tobacco Control 2003;12:161-167

See end of article for authors' affiliations

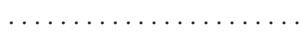

Correspondence to: Vanessa H Newburn, Department of Population Health Sciences, University of Wisconsin-Madison, 610 Walnut Street, WARF Building, Room 667, Madison, WI 53726, USA; vnewburn@wisc.edu

Received 23 August 2002. Accepted 22 January 2003
Background: Effective community based tobacco control programmes are critical for state and nationwide impact. However, there is little discussion in the literature of methods for setting local objectives which use locally collected data and account for historical variation in progress.

Objectives: To develop and illustrate a method that uses locally available birth certificate data to model trends in tobacco use during pregnancy among women giving birth, predict future prevalence, and use predictions to set community specific tobacco control objectives.

Data source: Vital statistics. Wisconsin standard birth certificates, 1990-2000, which record the smoking status of the mother during pregnancy.

Data analysis: Trends in the prevalence of smoking during pregnancy in Wisconsin statewide and in all counties ( $n=72$ ) were modelled using linear regression of log prevalence on year. Model fit was assessed using $\mathrm{R}^{2}$. Regression slopes, indicating estimated relative annual percentage change in prevalence, were used to predict prevalence in 2005 , and objectives were calculated as a $20 \%$ reduction from the predicted prevalence in 2005.

Conclusions: Modelling trends in the prevalence of smoking using locally collected data enables communities to set reasonable future tobacco control objectives that account for historical trends in progress.
L ocal community involvement in tobacco control initiatives is identified as a critical element to achieving populationwide reductions in tobacco use. In the USA, the Institute of Medicine suggests that communities of all sizes-states, counties, municipalities, and other groups-should adopt their own objectives and measure progress towards them if performance monitoring is to achieve its potential for community health improvement. ${ }^{1}$ These recommendations are supported by evidence from effective US tobacco control programmes in California, Massachusetts, Oregon, and Florida, which shows that the most successful approaches to reducing first or second hand tobacco exposure include multifaceted, community based programmes. ${ }^{2}$ In the developing world, recent efforts to establish regional tobacco control research agendas have focused on ways to implement comprehensive systems, to expand access to standardised and comparable data on tobacco use, and to address the need for a proper mix of central and local, community based action. ${ }^{34}$

However, there is limited discussion in the literature of appropriate ways to set objectives and evaluate progress at the local level. Objective setting and programme monitoring requires a consistent and comparable source of local data and a method for analysing and applying results in the community of interest. But even the most descriptive guidelines, such as Program and funding guidelines for comprehensive local tobacco control programs, ${ }^{2}$ and the Centers for Disease Control and Prevention's Best practices for comprehensive tobacco control programs, ${ }^{5}$ do not detail methods local communities can use to set appropriate objectives and monitor progress.

Lack of guidance for local community planning may result from a perceived lack of data for surveillance and planning at the local level. However, in the USA, vital statistics are a readily available and underutilised source of data for objective setting and local evaluation efforts in tobacco control. Since 1989, the US Standard Certificate of Live Birth has collected data on the prevalence of smoking during pregnancy among women giving birth. It contains a yes/no checkbox recording whether the mother smoked at any time during the pregnancy, and a box recording the average number of cigarettes smoked per day. ${ }^{6}$ Importantly, trends in smoking during pregnancy based on birth certificate data have been shown to be consistent with data from other sources. ${ }^{7-14}$

The prevalence of smoking during pregnancy is one important indicator of the burden of tobacco use among women, which has become a serious public health problem. The adverse health effects of smoking during pregnancy and postpartum are well documented, ${ }^{15-20}$ and the burden is extensive. The World Health Organization estimates that approximately 12-14 million worldwide smoked during their pregnancy in 1995, and an estimated 50 million or more are exposed passively to smoking during their pregnancy. ${ }^{15}$ In the USA alone, roughly one out of every eight pregnant women smoke, accounting for half a million births per year. ${ }^{16}$ As tobacco companies increase their marketing efforts to addict more smokers worldwide, they continue to focus special attention on "untapped markets" of women and children in both developed and developing countries. ${ }^{21}$ WHO recommends that every country conduct a baseline survey to document rates of active and passive smoking exposure among pregnant and postpartum women and use this to define national health objectives for 2005 and 2010 for health education, and to reduce exposure to smoke among pregnant women and infants. ${ }^{22}$

The purpose of this study was to develop and illustrate the use of a method for setting tobacco control objectives at the local level that utilises birth certificate data on the prevalence of smoking during pregnancy among women giving birth. The method requires modelling historical trends in tobacco use at the local level, predicting future prevalence of use, and using predictions to set a community specific objective for reduction 
in use. Counties in the state of Wisconsin are used for illustration. In 1990, Wisconsin ranked seventh highest in the country in smoking rates during pregnancy, with $22.9 \%$ of women giving birth reporting smoking on birth certificates. Over the last decade, this percentage decreased with the decline in smoking during pregnancy nationally; however, Wisconsin remains consistently above US levels. ${ }^{16}$

\section{METHODS}

\section{Data source}

The percentages of women giving birth who smoked during pregnancy for the years 1990 to 2000 in Wisconsin were obtained from US Standard Certificates of Birth maintained by the Wisconsin Vital Records Section, Wisconsin Bureau of Health Information. Information on smoking during pregnancy is recorded on the birth certificate by the attending physician, nurse, or other health professional at the time of delivery, and is obtained from the woman during prenatal care visits or at the time of delivery. The birth certificate records the answer to two questions: "Did you use tobacco at any time during the pregnancy?" (Yes/No); If "yes", "What was the average number of cigarettes smoked per day?".

\section{Data analysis}

Data were analysed separately at the state and individual county level. Analysis consisted of three steps: (1) modelling historical trends in the prevalence of smoking during pregnancy; (2) using models to predict future prevalence rates; and (3) using predicted prevalence to set community specific goals in tobacco control.

\section{Modelling trends}

First, the prevalence of smoking during pregnancy (that is, the proportion of births in which the birth certificate indicated that the mother smoked during the pregnancy) was calculated for each year, 1990-2000. Trends in prevalence for all counties $(\mathrm{n}=72)$ and the state over the 11 year period were then modelled using linear least squares regression of log of prevalence on calendar year. Modelling log transformed rates over time allows for decreasing rates of decline in prevalence over time, avoids prediction of negative future prevalence, and, in Wisconsin, more accurately described trends $\left(\mathrm{R}^{2}=0.98\right.$ for the state) than models using non-transformed prevalence. However, the meaning of results derived from models of log transformed rates is less easily explained than models of nontransformed rates. Estimates of approximate relative annual percentage change in prevalence were calculated for each regression by taking the exponential of the slope of the regression line $(\mathrm{m})$ and applying the formula $\left(100^{*}\left(\mathrm{e}^{\mathrm{m}}-\mathrm{l}\right)\right)$, a method described and used by the National Cancer Institute to estimate trends in cancer incidence and mortality for the SEER reporting system. ${ }^{23}$ Relative annual percentage change can be interpreted as a constant percentage change in prevalence from year to year.

\section{Predicting future prevalence}

The regression models were then used to predict county specific and overall state prevalence rates at a future point in time. The year 2005 was chosen for illustration, as it is the year the Wisconsin Tobacco Control Board will evaluate progress towards tobacco control initiatives, funded by an annual appropriation from the legislature of approximately \$15 million ( $\$ 3$ per capita), beginning in 2001 . To assess the ability of the models to predict future prevalence of smoking among pregnant women giving birth, a regression model of the first 10 years of data (1990-1999) (as described above) was used to predict county specific prevalence one year in the future (2000). These estimates were highly correlated with the actual (observed) county specific prevalence rates (Pearson correlation coefficient $=0.90)$. The regression model using all

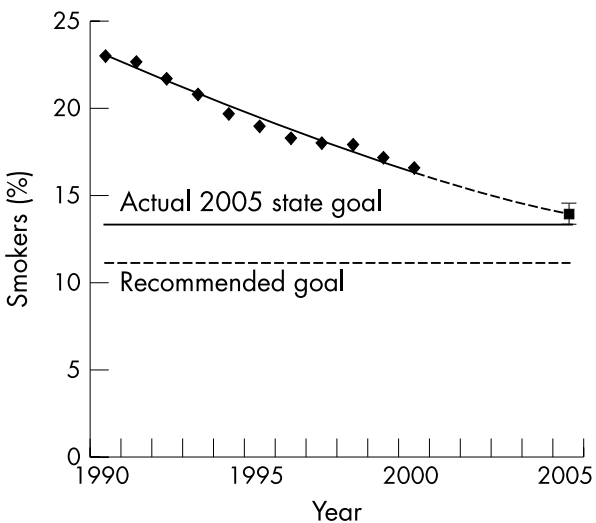

Figure 1 Trends in smoking during pregnancy for Wisconsin 1990-2000, and projected to 2005. Ninety five per cent confidence interval for projection is shown with error bars. Actual Tobacco Control Board goal for 2005 shown as solid line (represents a $20 \%$ reduction from observed rate in 2000). Proposed goal is calculated as a $20 \%$ reduction from the predicted prevalence estimate for 2005

11 years of data (1990-2000) was used to predict prevalence in the year 2005, with the expectation that accuracy of prediction decays for each additional year in the future. Ninety five per cent confidence intervals (95\% CI) were computed for the model estimates.

\section{Setting goals using predicted prevalence}

Finally, predicted prevalence in the year 2005 was used to illustrate a pragmatic method for setting community specific objectives in tobacco control. Objectives are set according to a percentage of the rate predicted by historical trend analysis. For illustration, we selected 2005 prevalence objectives that are $20 \%$ less than the 2005 prevalence rates that would be expected if fitted historical trends during the 1990s were maintained (a time when Wisconsin's annual tobacco control budget was approximately $\$ 1$ million). County specific as well as overall state objectives are set in this manner.

\section{RESULTS}

\section{Modelling trends}

In the state of Wisconsin over the 11 year period, the prevalence of smoking during pregnancy declined from $22.9 \%$ of pregnant mothers (1990) to $16.5 \%$ (2000). When modelled, this represents an average relative annual decrease in prevalence of $3.3 \%$ of the rate per year (95\% CI -3.7 to -2.9 ) (fig 1, table 1).

Across counties $(n=72)$ in the year 2000, the prevalence of smoking during pregnancy varied considerably, from $7.5 \%$ of pregnant women to $53.5 \%$ (median $18.8 \%$ ). Relative annual percentage change in prevalence ranged from $-5.5 \%$ per year to $1.6 \%$ per year (median $-1.9 \%)$ (table 1$)$. Most counties $(\mathrm{n}=$ 53) demonstrated trends that were significantly different from the state (that is, the 95\% CI for the country's relative annual percent change estimate did not overlap the point estimate for the state)-19 counties had faster rates of decline and 34 counties had slower rates of decline. Counties with larger numbers of annual births tended to have lower prevalence of smoking among pregnant women giving birth, and faster rates of decline in prevalence over time. Data from four counties and modelled trend estimates are shown in fig 2 and table 1. These counties illustrate county level variation in prevalence, annual relative percentage change in prevalence, and number of births, and highlight differences between county trends and the overall state average. 
Table 1 Variation in annual number of births, prevalence of smoking during pregnancy (observed in 2000), and relative annual percentage change in prevalence (modelled using simple linear regression of log prevalence on year, 1990-2000) across counties in the state of Wisconsin*

\begin{tabular}{|c|c|c|c|c|c|c|}
\hline County & $\begin{array}{l}\text { Average number } \\
\text { births/year }\end{array}$ & $\begin{array}{l}\text { Prevalence } 2000 \\
(\% \text { smokers ) }\end{array}$ & $\begin{array}{l}\text { Relative change } \\
\text { (\% smokers/year) }\end{array}$ & $95 \% \mathrm{Cl}$ & $\begin{array}{l}\text { Predicted } \\
\text { prevalence } 2005 \\
\text { (\% smokers) }\end{array}$ & $\begin{array}{l}\text { Recommended } 2005 \\
\text { goal (\% smokers) }\end{array}$ \\
\hline Pepin & 85 & 17.7 & -5.5 & -11.0 to 0.4 & 9.7 & 7.8 \\
\hline Kenosha & 2089 & 17.2 & -5.3 & -6.4 to -4.1 & 13.5 & 10.8 \\
\hline Calumet & 489 & 9.9 & -5.2 & -7.5 to -3.0 & 8.2 & 6.5 \\
\hline Milwaukee & 15498 & 14.8 & -5.2 & -5.6 to -4.8 & 11.6 & 9.3 \\
\hline Waukesha & 4127 & 9.7 & -5.1 & -5.7 to -4.4 & 7.3 & 5.8 \\
\hline Price & 166 & 15.2 & -4.7 & -6.8 to -2.5 & 12.8 & 10.3 \\
\hline La Crosse & 1314 & 13.5 & -4.6 & -7.7 to -1.3 & 9.9 & 7.9 \\
\hline Vilas & 183 & 27.7 & -4.6 & -6.6 to -2.5 & 19.0 & 15.2 \\
\hline Dane & 5151 & 10.4 & -4.5 & -5.2 to -3.8 & 8.7 & 7.0 \\
\hline Trempeleau & 337 & 16.2 & -4.4 & -7.0 to -1.7 & 12.3 & 9.8 \\
\hline Iron & 55 & 20.0 & -4.4 & -9.1 to 0.6 & 15.0 & 12.0 \\
\hline Green Lake & 212 & 16.0 & -3.9 & -6.3 to -1.5 & 11.8 & 9.4 \\
\hline Jefferson & 888 & 18.7 & -3.8 & -5.2 to -2.4 & 14.3 & 11.4 \\
\hline Racine & 2621 & 19.2 & -3.7 & -4.8 to -2.6 & 15.1 & 12.1 \\
\hline Grant & 552 & 15.6 & -3.7 & -5.5 to -1.9 & 13.5 & 10.8 \\
\hline Vernon & 346 & 16.2 & -3.6 & -6.7 to -0.4 & 10.9 & 8.7 \\
\hline Brown & 3077 & 15.8 & -3.5 & -5.2 to -1.9 & 12.9 & 10.4 \\
\hline Rock & 2061 & 20.4 & -3.5 & -4.7 to -2.3 & 17.0 & 13.6 \\
\hline Pierce & 408 & 13.6 & -3.4 & -5.2 to -1.5 & 11.8 & 9.4 \\
\hline Ozaukee & 928 & 7.5 & -3.3 & -6.2 to -0.3 & 7.9 & 6.3 \\
\hline Florence $\dagger$ & 42 & 30.6 & -3.3 & -7.7 to 1.4 & 20.2 & 16.2 \\
\hline Sawyer & 181 & 30.2 & -3.3 & -5.5 to -0.9 & 24.4 & 19.5 \\
\hline Clark & 464 & 16.1 & -3.2 & -5.0 to -1.5 & 12.2 & 9.8 \\
\hline St Croix & 795 & 14.2 & -3.1 & -4.6 to -1.6 & 11.2 & 9.0 \\
\hline Winnebago & 1858 & 17.8 & -3.0 & -3.7 to -2.3 & 14.4 & 11.5 \\
\hline Columbia & 615 & 19.5 & -3.0 & -4.1 to -1.9 & 16.2 & 12.9 \\
\hline Washington & 1437 & 12.8 & -2.9 & -4.2 to -1.5 & 11.6 & 9.3 \\
\hline Walworth & 1008 & 16.8 & -2.8 & -3.9 to -1.8 & 15.4 & 12.3 \\
\hline Douglas & 523 & 21.4 & -2.5 & -4.2 to -0.8 & 20.0 & 16.0 \\
\hline Dunn & 443 & 17.4 & -2.3 & -4.0 to -0.6 & 13.6 & 10.8 \\
\hline Waushara & 233 & 24.4 & -2.3 & -4.6 to 0.1 & 20.8 & 16.6 \\
\hline Monroe & 549 & 22.4 & -2.3 & -4.8 to 0.3 & 18.5 & 14.8 \\
\hline Oconto & 379 & 20.9 & -3.1 & -4.1 to -0.1 & 19.1 & 15.3 \\
\hline Sauk & 678 & 22.0 & -2.0 & -3.1 to -0.9 & 19.4 & 15.5 \\
\hline Dodge & 968 & 17.5 & -2.0 & -2.7 to -1.3 & 16.6 & 13.3 \\
\hline lowa & 282 & 17.5 & -1.9 & -4.3 to 0.4 & 15.6 & 12.5 \\
\hline Barron & 515 & 22.3 & -1.8 & -3.1 to -0.5 & 19.2 & 15.4 \\
\hline Bayfield & 1510 & 27.7 & -1.8 & -4.4 to 0.9 & 24.1 & 19.3 \\
\hline Waupaca & 616 & 21.5 & -1.8 & -3.4 to -0.1 & 20.5 & 16.4 \\
\hline Ashland & 212 & 27.7 & -1.7 & -3.6 to 0.1 & 25.7 & 20.5 \\
\hline Sheboygan & 1365 & 18.8 & -1.7 & -3.4 to 0.0 & 15.6 & 12.5 \\
\hline Marinette & 448 & 25.4 & -1.7 & -3.9 to 0.5 & 20.5 & 16.4 \\
\hline Eau Claire & 1126 & 17.6 & -1.7 & -2.8 to -0.6 & 16.0 & 12.8 \\
\hline Burnett & 146 & 22.8 & -1.6 & -4.2 to 1.2 & 26.9 & 21.5 \\
\hline Polk & 457 & 24.0 & -1.5 & -2.3 to -0.8 & 22.7 & 18.2 \\
\hline Marquette & 146 & 20.6 & -1.5 & -5.8 to 3.1 & 23.5 & 18.8 \\
\hline Juneau & 286 & 27.6 & -1.4 & -2.5 to -0.4 & 24.5 & 19.6 \\
\hline Lincoln & 332 & 24.6 & -1.4 & -3.5 to 0.8 & 22.4 & 17.9 \\
\hline Forest & 122 & 31.6 & -1.4 & -4.8 to 2.2 & 28.6 & 22.9 \\
\hline Chippewa & 661 & 21.7 & -1.3 & -3.3 to 0.8 & 20.2 & 16.1 \\
\hline Door & 272 & 20.7 & -1.2 & -5.2 to 2.9 & 17.3 & 13.9 \\
\hline Lafayette & 191 & 17.2 & -1.2 & -3.0 to 0.7 & 14.6 & 11.7 \\
\hline Langlade & 231 & 26.8 & -1.2 & -3.0 to 0.7 & 25.2 & 20.2 \\
\hline Washburn & 156 & 22.1 & -1.2 & -3.8 to 1.5 & 21.6 & 17.3 \\
\hline Adams & 170 & 35.4 & -1.1 & -2.9 to 0.8 & 32.2 & 25.7 \\
\hline Fond du Lac & 1165 & 18.7 & -0.9 & -2.2 to 0.4 & 19.6 & 15.7 \\
\hline Jackson & 209 & 27.5 & -0.9 & -2.1 to 0.3 & 25.2 & 20.1 \\
\hline Buffalo & 160 & 14.7 & -0.8 & -4.5 to 3.0 & 15.2 & 12.2 \\
\hline Outagamie & 2186 & 14.9 & -0.6 & -1.7 to 0.6 & 13.7 & 11.0 \\
\hline Wood & 964 & 22.3 & -0.5 & -1.7 to 0.7 & 20.6 & 16.5 \\
\hline Manito woc & 961 & 20.8 & -0.2 & -2.3 to 1.8 & 21.3 & 17.0 \\
\hline Portage & 807 & 16.3 & 0.0 & -2.7 to 2.6 & 16.4 & 13.1 \\
\hline Marathon & 1596 & 19.0 & 0.0 & -1.8 to 1.8 & 16.1 & 12.9 \\
\hline Richland & 201 & 19.4 & 0.0 & -2.1 to 2.2 & 18.9 & 15.1 \\
\hline Green & 396 & 20.9 & 0.0 & -2.3 to 2.4 & 18.3 & 14.6 \\
\hline Kewaunee & 225 & 19.6 & 0.0 & -2.7 to 2.8 & 16.0 & 12.8 \\
\hline Taylor & 239 & 19.8 & 0.1 & -1.8 to 1.9 & 18.9 & 15.1 \\
\hline Rusk & 184 & 31.1 & 0.3 & -3.0 to 3.6 & 25.6 & 20.5 \\
\hline Oneida & 350 & 26.0 & 0.3 & -1.3 to 1.8 & 27.5 & 22.0 \\
\hline Shawano & 469 & 23.2 & -0.5 & -2.5 to 3.5 & 23.3 & 18.6 \\
\hline Menominee & 102 & 53.8 & 1.1 & -2.0 to 4.4 & 52.4 & 41.9 \\
\hline Crawford & 200 & 26.8 & 1.6 & -1.6 to 4.8 & 26.2 & 20.9 \\
\hline STATE & 69025 & 16.5 & -3.3 & -3.7 to -2.9 & 13.8 & 11.0 \\
\hline
\end{tabular}



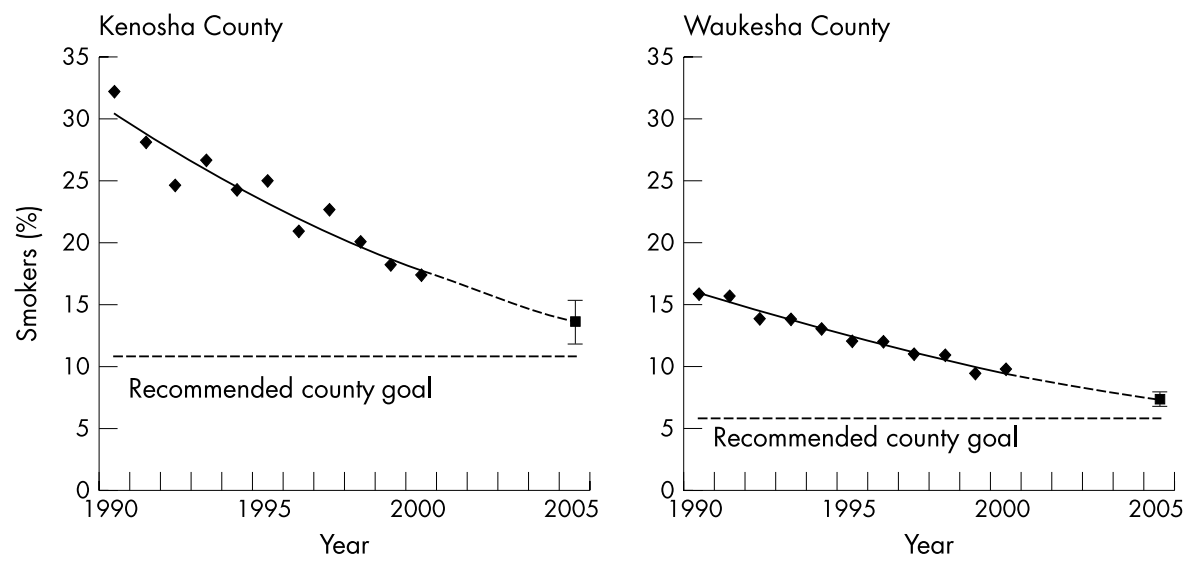

Figure 2 Variation in trends in prevalence of smoking during pregnancy across selected counties in Wisconsin, 1990-2000. Estimated prevalence in 2005 is shown with a $95 \%$ confidence interval. Proposed 2005 goals are county specific, and based on a $20 \%$ reduction from predicted prevalence in 2005.
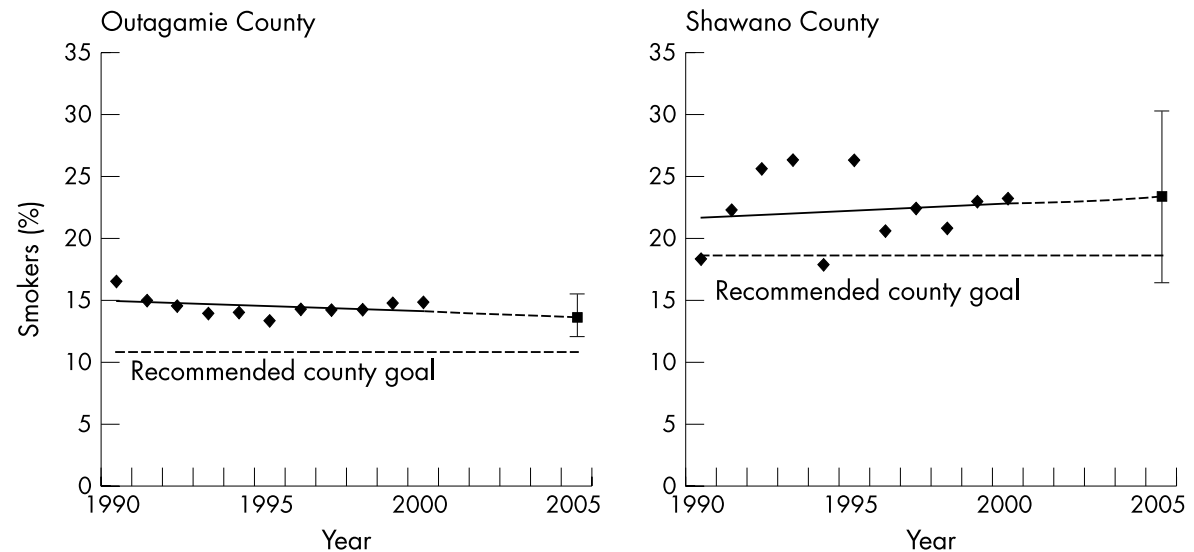

Predicting future prevalence

The regression models describing historical trends in prevalence of smoking during pregnancy were used to obtain estimates for prevalence in the year 2005. Overall, if the state trend continues, Wisconsin is predicted to have a prevalence of $13.8 \%$ of women giving birth who smoked during pregnancy (95\% CI 13.2 to 14.4) (fig 1). County estimates range from $7-52 \%$ in 2005 (median $17.0 \%$ ) (table 1).

\section{Setting goals using predicted prevalence}

Use of predicted prevalence to define tobacco control objectives at the state or county level is illustrated in figs 1 and 2. A model of state trends in smoking prevalence would suggest that Wisconsin is already predicted to come very close to meeting the current tobacco control board objective of $13.2 \%$ in 2005, an objective that reflects a $20 \%$ reduction in prevalence from the observed rate in 2000 . At the county level, if trends continue as modelled, 16 counties will meet or beat a county goal of a $20 \%$ reduction from the observed countywide prevalence in 2000. Six counties show historical trends of increasing prevalence (relative annual percentage change greater than zero), and are predicted to have slightly higher prevalence than currently observed in 2000 (table 1).

Rather than setting tobacco control objectives as a reduction from a recently observed rate, we suggest setting objectives as a percentage less than the rate predicted by historical trend analysis. At the state level, $20 \%$ less than $13.8 \%$ (the predicted prevalence estimate for 2005 ) is $11.0 \%$, the suggested goal for 2005 (fig 1). County specific goals were set in a similar manner, according to predicted prevalence in 2005 (fig 2, table 1).

\section{DISCUSSION}

This paper describes a method for utilising local data to set community specific tobacco control objectives. Using Wisconsin birth certificate data as an example, we demonstrated pro- nounced variation in the rates of smoking during pregnancy among women giving birth across all counties, and more importantly, variation in the rates of change over the past decade. Substantial local variation suggests the need for setting future tobacco control objectives at the local level that account for historical variation in progress across communities. Linear regression was used to model trends in prevalence over time, and models were used to predict future rates of smoking. This enables counties to set appropriate local objectives as a percent less than the predicted future prevalence, and enables states to assess variation in progress that may result from variation in tobacco control resources, population migration patterns, cultural beliefs, and changing sociodemographic characteristics of communities over time.

In practice, setting specific objectives would depend on the magnitude of planned interventions. For example, some communities may set an objective at the predicted future rate, assuming that the interventions and trends in population characteristics continue as in the past. Conversely, communities with substantial increases in tobacco control resources may set more aggressive objectives; or the choice of an appropriate percentage reduction from predicted might be set by the state programme. For example, counties in the lowest quartile of prevalence of smoking could be expected to achieve a 15\% reduction from predicted, whereas counties in the highest quartile could be expected to achieve a $20-25 \%$ reduction, since it may be easier to achieve reductions when the overall prevalence is high. Counties that historically kept the state rate high could be targeted for additional funds and programmatic support. These decisions could also be informed by estimates such as the relative effectiveness of interventions aimed at helping pregnant smokers quit smoking, which are provided by the Public Health Service Clinical Practice Guideline. $^{24}$ 
Local planning efforts may depend on state or national objectives that are inappropriate to local conditions or are based on a percentage reduction from one recently observed rate without accounting for past trends in progress. In Wisconsin, models indicate that nearly a quarter of counties and the state itself are expected to meet or beat current 2005 objectives (based on a $20 \%$ reduction from the observed rate in 2000) merely by continuing at the rate of change seen over the last 11 years. A few counties have increasing rates of smoking during pregnancy, suggesting that meeting this objective will be more difficult. Guidelines from effective comprehensive tobacco control programmes, such as those found in California and Massachusetts, help to fill this gap, by presenting many useful indicators and example objectives to guide specific local programme planning, which include monitoring the mean number of in-store tobacco signs in retail stores, increasing the number of community events conducted with smoke-free policies, and increasing the proportion of schools that provide smoking cessation programmes for faculty, staff, and students. ${ }^{25}{ }^{26}$ However, these documents do not provide systematic guidance to communities to suggest how historical trends in local progress might modify choice of an appropriate objective. The objective setting approach presented in this paper has the important virtue of systematically incorporating both historic trends and local variation in prevalence and rates of change of prevalence of smoking using birth certificate data.

This method also permits states to assess county level variation in trends over time and guide programme planning. In Wisconsin, model projections will serve as the "expected" rates of smoking in 2005 for each county, based on past intervention efforts and/or changes in sociodemographic and economic community characteristics. The rates observed in 2005 can subsequently be compared to these expected rates, to assess potential variation in progress. Counties that beat their predicted prevalence could be compared with those that did not, and reasons for variation can then be explored. In Wisconsin, the more populated counties (for example, Dane and Waukesha) have the lowest rates of smoking during pregnancy whereas sparsely populated areas tended to have much higher rates (for example, Shawano county), illustrating geographic variation and potentially warranting more aggressive marketing of a telephone quitline in high prevalence areas, for example. Menominee county, an entirely native American Indian reservation, has the highest rate in the state, illustrating variation potentially explained by sociodemographic factors and suggesting a need for culturally appropriate programmes. Finally, variation in programmatic factors is evident-for example, in smoke-free restaurant policies, which have greater success in more urban communities, and advertising campaigns that vary across communitiesindicating a need for increased funding in certain areas. Subgroup analyses could be performed to examine trends by age, race, education, and even financial (such as Medicaid) status. Ideally, policy makers would like to compare trends in tobacco use in their communities with other communities, to assess whether their programmes are more effective in reducing tobacco use. Greater progress compared with predicted trends would suggest that community based programmes are having a greater effect, although many factors must be considered in such an evaluation design. ${ }^{27}$

Importantly, the method of data analysis and local objective setting described in this paper could be applied to other consistent sources of local data collected over time in communities. For example, the Behavioral Risk Factor Surveillance System (BRFSS) (all states since 1996), the National Youth Tobacco Survey (YTS) (since 1999), and/or the Youth Risk Behavior Survey (since 1991) all offer the flexibility of sub-state estimates of youth tobacco use prevalence. The YTS will be most useful in the future, when several years of data become available for trend analysis. Birth certificate data, on

\section{What this paper adds}

International and US tobacco control programmes identify progress at the local community level as a critical component to achieving overall reductions in the burden of tobacco use. However, there is little discussion in the literature of ways to assess past trends and plan and monitor future progress at the local community level. Often, state and national tobacco control goals are set as a moderate decrease (for example, $20 \%$ over a five year period) from a recently observed prevalence of smoking. These goals, based on observed prevalence at one point in time, do not account for trends in change, and often are not adequate for community planning at the local level because of variation in local conditions.

This paper describes and illustrates the use of a three step method to set tobacco control objectives at the county level. Data on the prevalence of smoking during pregnancy is obtained from the US Standard Birth Certificate, an underutilised source of routinely collected data on tobacco use at the local level. The method is illustrated using data from the state of Wisconsin and involves modelling historical trends in prevalence of smoking during pregnancy among women giving birth at the state and individual county level. Models are then used to predict future prevalence of use, and set objectives as a percentage less than an estimated future prevalence. This approach to setting objectives could be applied to other sources of data collected at the local level to improve community planning efforts and reduce the burden of smoking in communities.

the other hand, provides information on all registered births (that is, it is not a survey estimate), and is more widely available over the past decade. Additionally, question items are consistently stated across jurisdictions in the USA, data are simple to analyse, ${ }^{1}$ and, in general, trends in smoking rates based on birth certificate data have been confirmed with data from other sources, including the Pregnancy Risk Assessment Monitoring System, the National Survey of Family Growth, and the National Pregnancy and Health Survey in estimating the prevalence of smoking during pregnancy. ${ }^{7-14}$ In validation studies, smoking ascertainment on the birth certificate was found to be $70-85 \%$ complete. ${ }^{13} 1428$

The choice of an appropriate data source should consider the relevance to local conditions, and communities choosing to use birth certificate data to set local objectives should be aware of some important limitations. First, the relative availability and accessibility of birth certificate data should not be the only reason for using it to inform community planning. Planning efforts aimed specifically at reducing the prevalence of smoking during pregnancy among women giving birth may lead to narrow cessation interventions. However, population based interventions could also influence the proportion of women smoking during pregnancy by reducing rates of initiation in children and adolescents, and targeting people of all age groups with broad based strategies.

Second, though most US states collect comparable information, a few do not. During the 1990s, the number of US states that collected comparable data on smoking during pregnancy from the birth certificate changed, with no reporting from California and South Dakota for the entire decade, and Indiana and New York State beginning reporting in 1999. This is not seen as a serious limitation, however, since the range in the percentage of all birth certificates collecting comparable information about smoking status increased from $75 \%$ in 1990 to $87 \%$ in $1999 .^{16}$

Outside the USA, survey data are more commonly used to estimate prevalence of smoking during pregnancy. In England, for example, as part of a smoking and pregnancy initiative, the Health Education Authority carried out a series of 
annual surveys using quota sampling of pregnant women from 1992 to 1997 to measure behaviour in relation to smoking during pregnancy. ${ }^{29}$ In Italy, the prevalence of smoking among pregnant women has been estimated through casecontrol studies. ${ }^{30}$ Much more limited information is available in developing countries, where progress towards universal birth registration is underway, particularly in the Sub-Saharan Africa and South Asia regions. ${ }^{31}{ }^{32}$ Demonstrating effective use of birth certificate smoking data in the USA may be useful to these nations as they make progress towards ensuring that important information is collected and registered at the time of birth. However, the cost of implementing system-wide change is an important consideration.

Third, when modelling local trends in smoking among women giving birth, one inevitably encounters difficulty in communities where there are few absolute numbers of births. This scarceness of data can reduce the ability to accurately predict prevalence several years in the future. However, as illustrated in Wisconsin, even smaller rural counties with populations under $10000(n=5)$, according to the US Census in 2000, have an average of 81 births each year. This limitation could be overcome by grouping adjacent communities matched on certain characteristics of interest. For example, data from neighbouring counties with shared programmes, organisational goals, or cultural characteristics might analyse a combined dataset to set group objectives. Alternatively, data from counties with similar overall prevalence of smoking or similar historical trends in prevalence might be combined to improve confidence in predicted rates.

Finally, estimates of the prevalence of smoking among pregnant women also tend to be somewhat lower when data collected on birth certificates is used. ${ }^{11}{ }^{14}{ }^{33}$ Several studies have suggested that the lack of specificity in the birth certificate questions is the principal factor accounting for reported differences in levels of smoking during pregnancy. ${ }^{13}{ }^{14}$ Additionally, information is collected only on women whose pregnancies result in live birth. Smoking is a major cause of spontaneous abortion and still birth, ${ }^{34-37}$ and these are not measured with birth certificate data. Underreporting may also result from women inaccurately reporting smoking behaviour to their health care provider. Particularly in cases of poor birth outcome, the mother might be less willing to admit to having smoked at all during pregnancy if asked about lifestyle factors after the delivery. ${ }^{16}$ Other reasons for underreporting may include the failure of the physician to inquire about smoking behaviour or the incorrect transfer of information from the prenatal care record to the certificate at the time of delivery, and these limitations should be considered.

In summary, this paper describes and illustrates the usefulness of a method for setting community specific tobacco control objectives that uses model estimates to set reasonable objectives for the future. While tobacco control programmes indicate that local initiatives are an important component of reducing tobacco use, few methods are available to guide objective setting that account for local variation in past progress. The method described uses the US Standard Birth Certificate as a source of routinely collected local data that can be used to determine the prevalence of smoking during pregnancy, an important indicator of the burden of tobacco use, and to set local objectives. Though the USA is the only country known to us to collect information on smoking during pregnancy on the birth certificate, the event and registration of birth may represent an equally useful opportunity for data collection on smoking for other countries throughout the developed and developing world.

\section{ACKNOWLEDGEMENT}

We thank staff at the Bureau of Health Information, Wisconsin Department of Health and Family Services, for providing data from Wisconsin birth certificates, and Kate Kvale and Ann Christiansen for their helpful contributions. This research was supported, in part, through a contract from the Wisconsin Tobacco Control Board, and by grant 5 T32 HS00083 from the Agency for Healthcare Research and Quality.

\section{Authors' affiliations}

V H Newburn, P L Remington, P E Peppard, Department of Population Health Sciences, University of Wisconsin-Madison, Madison, Wisconsin, USA

\section{REFERENCES}

1 Institute of Medicine (USA) Committee on Using Performance Monitoring to Improve Community Health. Improving health in the community: a role for performance monitoring. Washington DC: National Academy Press, 1997.

2 National Association of County and City Health Officials (NACCHO). Program and funding guidelines for comprehensive local tobacco control programs. Accessed 16 August 2002. URL: http://www.naccho.org/prod91.cfm

3 Samet J, Yach D, Taylor C, et al. Research for effective global tobacco control in the 21 st century: report of a working group convened during the 10th World Conference on Tobacco or Health. Tobacco Control 1998;7:72-7

4 Baris E, Brigden L, Prindiville J, et al. Research priorities for tobacco control in developing countries: a regional approach to a global consultative process. Tobacco Control 2000;9:217-23.

5 Centers for Disease Control and Prevention. Best practices for comprehensive tobacco control programs. Atlanta, Georgia: Centers for Disease Control and Prevention, National Center for Chronic Disease Control and Prevention and Health Promotion, Office on Smoking and Health; August 1999.

6 Tolson GC, Barnes JM, Gay GA, et al. The 1989 revision of the U.S. standard certificates and reports. Vital Health Statistics 1991;4:28.

7 Abma JC, Chandra A, Mosher WD, et al. Fertility, family planning, and women's health: new data from the 1995 National Survey of Family Growth. Vital Health Statistics 1997:23:19.

8 Ventura SJ, Martin JA, Curtin SC, et al. Report of final natality statistics, 1996. Monthly vital statistics report. 1998;46(1 1)

9 Mathews TJ. Smoking during pregnancy, 1990-1996. Hyattsville, Maryland: National Center for Health Statistics; 1998.

10 Ventura SJ. Using the birth certificate to monitor smoking during pregnancy. Public Health Rep 1999;114:71-3.

11 Centers for Disease Control and Prevention, Division of Reproductive Health, National Center for Chronic Disease Prevention and Health Promotion (USA). PRAMS 1995 surveillance report. Atlanta, Georgia: CDC, 1998.

12 National Institute on Drug Abuse (USA). National pregnancy and health survey - drug use among women delivering live births, 1992. Rockville, Maryland: US Department of Health and Human Services, 1996.

13 Buescher PA, Taylor KP, Davis MH, et al. The quality of the new birth certificate data: a validation study in North Carolina. Am J Public Health 1993;83: $1163-5$

14 Dietz PM, Adams MM, Kendrick JS, et al. Completeness of ascertainment of prenatal smoking using birth certificates and confidential questionnaires: variations by maternal attributes and infant birth weight. Am J Epidemiol 1998;148: 1048-54

15 Windsor R. Smoking, cessation and pregnancy. In: Samet JM, Yoon SY, eds. Women and the tobacco epidemic: challenges for the 21 st century. Canada: World Health Organization in collaboration with the Institute for Global Tobacco Control, Johns Hopkins School of Public Health, 2001:147-63

16 Mathews TJ. Smoking during pregnancy in the 1990s. National Vital Statistics Report. 28 August 2001;49(7).

17 US Department of Health and Human Services. Women and smoking: a report of the Surgeon General. Rockville, Maryland: US Department of Health and Human Services, Public Health Service, Office of the Surgeon General, 2001.

18 Walsh RA. Effects of maternal smoking on adverse pregnancy outcomes: examination of the criteria of causation. Human Biology 1994:66: 1059-92

19 Schlaud M, Kleemann WJ, Poets CF, et al. Smoking during pregnancy and poor antenatal care: two major preventable risk factors for sudden infant death syndrome. Int J Epidemiol 1996;25:959-65.

20 US Department of Health and Human Services. The health benefits of smoking cessation. A report of the Surgeon General, 1990. Rockville, Maryland: Public Health Service, Centers for Disease Control, Office on Smoking and Health, 1990. (DHHS Publication No (CDC) 90-8416.)

21 World Health Organization. Tobacco free initiative. Accessed 17 January 2002. URL: http://tobacco.who.int/en/fctc/index.html

22 US Public Health Service, Department of Health and Human Services. Healthy People 2010: national health promotion and disease prevention objectives. Washington DC: US Public Health Service, 2000.

23 Ries L, Eisner M, Kosary C, et al, eds. SEER Cancer Statistics Review, 1973-1997. Bethesda, Maryland: National Cancer Institute, 2000. (NIH Publication No. 00-2789.) 
24 Fiore M, Bailey W, Cohen S, et al. Treating tobacco use and dependence: Clinical Practice Guideline. Rockville, Maryland: US Department of Health and Human Services, Public Health Service, June 2000

25 Tang H, Koumiian K, Cowling D, et al. Local Program Evaluation Planning Guide-draft August 2001. California Department of Health Services, Tobacco Control Section. Accessed 6 January 2003. URL: http://www.dhs.cahwnet.gov/tobacco/html/publications.htm

26 Connolly G, Robbins H. Designing an effective tobacco control program - Massachusetts. Massachusetts Department of Public Health. Accessed 6 January 2003. URL: http://www.state.ma.us/dph/mtcp/ report/design.htm

27 Cook T, Campbell D. Quasi-experimentation: design and analysis issues for field settings. Chicago: Rand McNally College Publishing Co, 1979.

28 Piper JM, Mitchel EFJ, Snowden M, et al. Validation of 1989 Tennessee birth certificates using maternal and newborn hospital records. Am J Epidemiol 1993;137:758-68.

29 Owen L, McNeill A, Callum C. Trends in smoking during pregnancy in England, 1992-7: quota sampling surveys. BM 1998;317:728.
30 Chatenoud L, Chiaffarino F, Parazzini F, et al. Prevalence of smoking among pregnant women is lower in Italy than England. BM 1999;318:1012

31 United Nations Children's Fund (UNICEF). UNICEF Statistics: Birth Registration.Accessed 5 January 2003. URL: http://www.childinfo.org/ eddb/birthreg/index.htm

32 United Nations Children's Fund (UNICEF). UNICEF Statistics: Delivery Care. Accessed 5 January 2003. URL: http:// www.childinfo.org/eddb/maternal/index.htm

33 Ebrahim SH, Floyd RL, Merritt RK, et al. Trends in pregnancy-related smoking rates in the United States, 1987-96. JAMA 2000;283:361-6. 34 Ness R, Grisso JA, Hirschinger N, et al. Cocaine and tobacco use and the risk of spontaneous abortion. N Engl J Med 1999;340:333-9.

35 Walsh R. Effects of maternal smoking on adverse pregnancy outcomes: examination of the criteria for causation. Human Biology 1994:66:1059-92.

36 Shiverick K, Salafia C. Cigarette smoking and pregnancy I: ovarian, uterine, and placental effects. Placenta 1999;20:265-72.

37 Raymond E, Cnattingius S, Kiely JL. Effects of maternal age, parity and smoking on the risk of stillbirth. Br J Obstet Gynaecol 1994;101:301-6.

\section{Clinical Evidence-Call for contributors}

Clinical Evidence is a regularly updated evidence based journal available worldwide both as a paper version and on the internet. Clinical Evidence needs to recruit a number of new contributors. Contributors are health care professionals or epidemiologists with experience in evidence based medicine and the ability to write in a concise and structured way.

Currently, we are interested in finding contributors with an interest in the following clinical areas:

Altitude sickness; Autism; Basal cell carcinoma; Breast feeding; Carbon monoxide poisoning; Cervical cancer; Cystic fibrosis; Ectopic pregnancy; Grief/bereavement; Halitosis; Hodgkins disease; Infectious mononucleosis (glandular fever); Kidney stones; Malignant melanoma (metastatic); Mesothelioma; Myeloma; Ovarian cyst; Pancreatitis (acute); Pancreatitis (chronic); Polymyalgia rheumatica; Post-partum haemorrhage; Pulmonary embolism; Recurrent miscarriage; Repetitive strain injury; Scoliosis; Seasonal affective disorder; Squint; Systemic lupus erythematosus; Testicular cancer; Varicocele; Viral meningitis; Vitiligo

However, we are always looking for others, so do not let this list discourage you.

Being a contributor involves:

- Appraising the results of literature searches (performed by our Information Specialists) to identify high quality evidence for inclusion in the journal.

- Writing to a highly structured template (about 2000-3000 words), using evidence from selected studies, within 6-8 weeks of receiving the literature search results.

- Working with Clinical Evidence Editors to ensure that the text meets rigorous epidemiological and style standards.

- Updating the text every eight months to incorporate new evidence.

- Expanding the topic to include new questions once every 12-18 months.

If you would like to become a contributor for Clinical Evidence or require more information about what this involves please send your contact details and a copy of your CV, clearly stating the clinical area you are interested in, to Claire Folkes (cfolkes@bmigroup.com).

\section{Call for peer reviewers}

Clinical Evidence also needs to recruit a number of new peer reviewers specifically with an interest in the clinical areas stated above, and also others related to general practice. Peer reviewers are health care professionals or epidemiologists with experience in evidence based medicine. As a peer reviewer you would be asked for your views on the clinical relevance, validity, and accessibility of specific topics within the journal, and their usefulness to the intended audience (international generalists and health care professionals, possibly with limited statistical knowledge). Topics are usually 2000-3000 words in length and we would ask you to review between 2-5 topics per year. The peer review process takes place throughout the year, and our turnaround time for each review is ideally 10-14 days.

If you are interested in becoming a peer reviewer for Clinical Evidence, please complete the peer review questionnaire at www.clinicalevidence.com or contact Claire Folkes (cfolkes@bmigroup.com). 